\title{
Neurophysicological findings after anterior communicant artery aneurysm surgery (AcomA): a literature review
}

\author{
Camila B. dos Santos ${ }^{1}$, Simone C. de Carvalho ${ }^{2}$, Eberval G. Figueiredo ${ }^{3}$, Manoel J. Teixeira ${ }^{4}$ \\ Divisão de Clínica Neurocirúrgica do HCFMUSP
}

\begin{abstract}
Objective: To present a literature review of cognitive disorders in patients operated on anterior communicant artery aneurysm (AcomA). Methods: Literature was searched (PubMed) from 1996 to 2009 using "aneurysm", "surgery" and "neuropsychological evaluation" as keywords. Only papers describing postoperative neuropsychological findings were included in this review. Results: A great deal of the retrieved papers noted alterations of intellectual, executive functions and memory (episodic and semantic). Some authors explain these memory deficits as secondary to the executive dysfunction or ischemia in related areas. Other papers noted secondary alterations after temporary clipping (worse alert and selective attention). Majority of deficits improve with time, however, long periods of temporary clip are associated with persistent deficits. Conclusion: The studies are scarce in the Brazilian literature that valued thoroughly neuropsychological alterations after AcomA surgery, correlating data with the resection or not of the straight gyrus, with the presence or not of vasoespasm and alterations in the quality of life. There were not found, up to the moment, studies in which these patients were valued pre and post surgery.
\end{abstract}

\section{KEYWORDS}

Cognitive deficit, aneurysm, anterior communicant artery.

\section{RESUMO}

Alterações neuropsicológicas após cirurgia de aneurisma de artéria comunicante anterior Objetivo: Apresentar extensa revisão de literatura sobre alterações cognitivas em pacientes operados de aneurismas de artéria comunicante posterior. Métodos: Realizou-se pesquisa na base de dados PubMed utilizando as palavras-chave "aneurysm", "surgery" e "neuropsychological evaluation". Somente trabalhos publicados entre 1996 e 2009 descrevendo achados pós-operatórios foram incluídos. Resultados: Grande número de artigos descrevem alterações de funções intelectuais, executivas e de memória (episódica e semântica). Déficits de memória podem ser secundários à disfunção executiva ou isquemia. Outros artigos relatam alterações ocorridas após clipagem temporária, principalmente na função de atenção seletiva. A maioria dos déficits melhora com o tempo, contudo períodos prolongados de clipagem temporária têm sido associados com disfunções permanentes. Conclusão: Não há estudos até o momento incluindo avaliações pré e pós-operatórias e os estudos em literatura nacional são escassos. O papel da hemorragia, do vasoespasmo, da hidrocefalia, da ressecção do giro reto e da clipagem temporária ainda não está estabelecido.

\section{PALAVRAS-CHAVE}

Déficit cognitivo, aneurisma, artéria comunicante anterior.

1. Neuropsicóloga, mestre pela Faculdade de Medicina da Universidade de São Paulo (FMUSP).

2. Neuropsicóloga.

3. Supervisor, chefe do Grupo de Neurocirurgia Vascular da Divisão de Clínica Neurocirúrgica do Hospital das Clínicas (HC) da FMUSP.

4. Professor titular da disciplina de Neurocirurgia da FMUSP e diretor da Divisão de Clínica Neurocirúrgica do HCFMUSP. 


\section{Introduction}

Ruptured aneurysms are frequently associated with neurological morbidity, greatly related to vasospasm. This rupture is susceptible of producing motor and cognitive alterations, depending on the affected region. Aneurysms of anterior communicating artery (AcomA) are prone to cause cognitive deficits and consequently difficulties in the social, familiar and professional reintegration, in spite of good neurological global recovery, since these deficits may impact negatively the daily activities. Some controversy exists whether these deficits are due to the bleeding by itself, occurrence of vasospasm, temporary clipping or gyrus rectus resection.

The present study aims to elucidate questions about the cognitive alterations in patients with aneurysm of AcomA. The review was focused on Medline and PubMed data, in the period of 1996 up to 2009, using terms such as "aneurysm", "surgery" and "neuropsychological evaluation".

\section{Literature review}

In 1996, D'Esposito e cols. ${ }^{3}$ studied the memory recuperation and the executive functions in 10 patients who suffered aneurysm rupture and AcomA surgery. Patients were tested at two moments after the surgery (2 and 3 months) and divided into two groups, according to the severity of the executive damage.

In the first evaluation, both groups had severe anterograde amnesia, but only the patients with executive severe losses had retrograde amnesia. After two months, in both groups persisted the severe anterograde amnesia, whereas, the dysexecutive group revealed significant improvement of executive deficits and the retrograde amnesia. Patients with major loss of executive functions presented bilateral frontal injury more extensive than others. According to the authors, these findings suggest that as time goes by changes occur in the cognitive profile after an AcomA rupture. The authors conclude that the time after the rupture and its location are of extreme importance to define the neurophysicological profile and to determine the cognitive underlying mechanisms.

Rousseaux e cols. (1996), ${ }^{10}$ investigated intellectual functions and memory at two moments after the AcomA rupture ( 3 weeks to 4,5 months and 10 to 16 months). Twenty-one patients were evaluated, with injuries in the frontal region and basal areas, of the cingulate gyrus, caudate and corpus callosum. In the first evaluation, it was noted decline of the intellectual capacities, being more severe in the performance of the IQ, instead of the learning. The cognitive specific evaluations revealed increase in the time of execution, but relatively preserved performance. In the Stroop test, the deficit of focused attention was moderated and the performance in the Wisconsin Card Sorting Test was satisfactory in most of the cases. Significant memory deficits were observed at short and long verbal terms, visual space learning and in the access to the semantic memory.

In the second evaluation, the intellectual performance improved and the cognitive specific disorders frequently improve altogether. Most of the performances were better explained by the severity of the injuries in the left cingulate cortex and corpus callosum. The authors state that the cognitive profile found in this study differs from the classic descriptions, and that patients improve gradually, since the results appear different and better depending upon the time of the evaluation.

Hütter and Gilsbach ${ }^{5}$ evaluate cognitive immediate sequels after AcomA surgery. Between 1 and 13 days of the surgery, they examined 28 patients and noticed that they presented deficits in some aspects of the attention, language, short and long term memory. There were not observed alterations resulting from the place, premature rupture or surgical approach of the AcomA. Meantime, the vessel temporary clipping was associated to a worse alert and selective attention.

The duration of the temporary clipping was associated to worst memory of short term and reduction of the alert phase. Partial resection of the straight gyrus brought into worse short term memory. The authors ended which determined proceedings and events in aneurysms surgeries can have neuropsychological effects. They say that to confirm the considered results is necessary a study with bigger sample.

Thomas-Anterion e cols. (1996) ${ }^{14}$ valued patients after rupture and AcomA surgery. They compared 7 patients who stayed in amnesia, with 11 patients without cognitive complaints and 18 normal controls. All patients were submitted to tests of implicit/explicit memory and tests that are sensitive to the dysfunction of frontal lobe. The cognitive performance of 11 patients without cognitive complaints revealed evidences of frontal dysfunction for explicit memory. Seven patients with amnesia revealed evidence of functional frontal dysfunction, deficit of explicit memory and anosognosia. All the patients revealed preservation of the implicit memory in tasks of proceeding. The authors conclude that the nature of this functional syndrome is questionable.

Diamond e cols. (1997) ${ }^{4}$ say that the rupture and surgery of AcomA can result in important damages wrapping the memory, executive functions, confabulations and personality's change. They noted that cerebral areas traditionally connected with the amnesia are not damaged, but even though, amnesia can happen. They 
also present, normal performance in visuo-constructive tasks, like in the Rey complex figure, meantime, the recuperation is frequently damaged. The authors valued 10 patient post-rupture of AcomA, using the Rey-Organizational, i.e., with strategies of organization to increase the immediate recuperation. The considered results were: improvement of the immediate recuperation with organization strategies in patients with amnesia; with the strategies patients with and without amnesia had the informations back in comparable extension after $30 \mathrm{~min}$; two groups of patients with amnesia appeared: those with loss in the acquisition and loss in the recuperation. The authors conclude that these results have important implications for to the use of strategies of organization in the cognitive treatment improving the validity and reliability of the patients evaluation.

In 1997, Bindschaedler e cols. ${ }^{2}$ valued 56 patients at different moments after the aneurism clipping. The neuropsychological evaluation carried out after the acute phase showed intellectual sequel in two thirds of the patients, evolving in most of the cases into selective damage of the executive capacities and memory in the chronic phase. A case of amnesia was observed only anterograde, probably resulting from the inevitable inclusion of the hypothalamic artery in the clip during the surgery. A common find was the damage of the performance in executive and memory tests. In a minority of patients disorders of the language, visuoperspective and visuoconstructive were found, probably connected to hemodynamic changes. For the authors, the intellectual global damage, patients with amnesia and persistent confabulations for 4-15 weeks post-surgeries, are associated to the interruption of the professional activity. The executive damages of memory and behavior disturbances, like those found in patients with frontal lobe diseases, are associated to a less probability of job. The pre and post operative angiography are not good predictors of cognitive result in the long term: normal angiography had not necessarily in a normal neuropsychological result, as well as anormal angiography might have a normal neuropsychological result. In contrast, in the post-operative angiography, there was relation between anormality and laterality, $\mathrm{X}$ language disorders, visuoperceptive/visuoconstructive damages, as well as a relation between the side of the craniotomy and the deficits type.

Silva (1998) ${ }^{11}$ investigated the performance of post-surgical patients of AcomA and PcomA in tests of memory, verbal fluency, intelligence and frontal functions. There were used the scales Wechsler of intelligence and memory. Only the patients of AcomA presented deficits of memory of long term for verbal material and in tasks that value Verbal IQ. The patients of PcomA presented visuomotor deficit in the test Labyrinth of Porteus, which examines include the capacity of projection.
According to the author, the results suggest that the rupture of the AcomA can induce selective deficits of memory and that they can be due to a lack of blood irrigation in cerebral structures intimately related to the modulation of the memory, such as the basal prosencephalon, septum and the fornix.

In 2000, Mavaddat e cols. ${ }^{7}$ investigated the neuropsychological changes and the influence of the time for aneurysm clipping after subarachnoid hemorrhage. For cognitive evaluation, there was used the "Cambridge Neuropsychological Test Automated Battery". Patients with age under 70 years old, with favorable result in the Glasgow scale (4 or 5) were studied between 6 and 24 months after the surgery. The patients were divided in two groups: recent surgery (0-3 days) and late surgery (after 3 days). The neuropsychological analysis was done by inspectors who did not know the time of the surgery. Fortyseven patients were valued with middle age of 51.5 years. They were compared by age and IQ respected (Intelligence quotient) with controls, using the "National Adult Reading Test".

They noticed that the patients presented deficits in tasks of verbal fluency, recognition and memory of space work. This profile of deficits is similar to the considered ones in patients with injuries of the frontal lobe.

Significant differences were not found in the cognitive performance of groups of recent and late surgery. The authors ended that after the surgery for ruptured AcomA, even the patients who reached neurological favorable result, were presenting cognitive significant deficits, principally in the tests that value functions of the frontal lobe and that the late surgery does not increase the risk of neuropsychological inability.

Hütter e cols. $(2001)^{6}$ valued the effects of the acute bleeding and of the surgery in the capacity of life after subarachnoid hemorrhage (SAH). There were valued 116 patients ( 77 women and 39 men), with age varying between 30 and 69 years old, during 4 to 5 years after the SAH. They used a questionnaire of quality of life. $74.1 \%$ had suffered surgery under 72 hours. Damages were found in the capacity of life in the aneurysms of cerebral middle artery (MCA), but not in patients with aneurysm of the posterior communicant artery, even when the resection of the straight gyrus was done. The temporary clipping was associated to bigger complaints in some areas of the quality of life. Disturbances of cerebrospinal fluid circulation and the presence of intraventricular hemorrhage lead into bigger damages in the daily life. No resulting alteration was found of vasoespasm.

Multivaried analysis showed that the age of the patient, the neurological state in the admission (scale Hunt Hess) and the standard of the hemorrhage are significantly predictors of SAH psychosocial sequels. 
In 2003, Simard e cols. ${ }^{12}$ studied the impact of the desexecutive syndrome in the episodic and semantic memory, in 59 patients with AcomA retrospectly examined. All the patients were valued by several tests of episodic memory (Verbal Rey Auditory Learning Test, Rey Complex Figure Test, Wechsler Memory Scale), semantic memory (verbal fluency) and standard tests of executive functions (Trail Making Test, Maze Tests, Wisconsin Card Sorting Test). There was a positive correlation between executive dysfunction and difficulties in the recuperation of the episodic and semantic memories. The patients were divided in two sub-groups: with low and high functioning of the frontal lobe. They noticed that the AcomA with low functioning of the frontal lobe were particularly defective in the spontaneous memory (immediate and late), while the recognition was preserved in two sub-groups. No sub-group presented an abnormal oblivion with the passage of the time that suggests a deficit of recuperation instead of a damage in the retention.

Szatkowska e cols. (2004) ${ }^{13}$ investigated the function of the ventromedial prefrontal cortex in the temporal and spatial memory. There were valued patients who did aneurysms of the posterior communicant artery and normal controls (C). The patients were divided in three groups: 1) with resection of the left straight gyrus (LSG+); 2) with resection of the right straight gyrus (RSG+) and 3) without resection of the straight gyrus (SG-). There were used two tests of memory, of temporal and space order. In the temporal test, the LSG + and RSG+ groups presented worse performance than the controls, once the SG- group did not present significant difference of the controls. In the space test, as the groups with resection of the SG as the groups without resection of the SG did not show significant differences of the control group. The results suggest that the cortex ventromedial prefrontal cortex is wrapped in the memory for contextual information.

Akyuz e cols. (2005) $)^{1}$, execute a study aiming to investigate possible effects in the functioning of the frontal lobe, for the application of temporarily clip in patients with rupture of AcomA. There were selected 40 patients who were operated in the period of 96 hours after the rupture. All of them were in the degree 1 or 2 of the Hunt-Hess scale. Of 40 patients, 22 patients were using temporarily clip (group A) and 18 patients were not using (group B).

Two groups were compared with 20 volunteers (group C) without neurological and psychiatric diseases. The middle time of the temporary occlusion was $8.2+/-2.9$ min.

They noticed that improves happened in the frontal functioning of the Group B in the long term and in the continuation of the group A, the cognitive deficits were persisting in the long term, principally in the patients with temporary clipping duration superior to $9 \mathrm{~min}$.
According to the authors, the results emphasize that the negative effects of the temporary occlusion in cognitive changes take place before the ischemic brain damage. So, the negative effects of the temporary clipping in the cognitive functioning should not be neglected by surgeons during the surgery.

In 2006, Myers e cols. ${ }^{8}$ pointed to the importance of considering the etiology of the memory deficits in patients with amnesia, since such deficits can be found in patients with alteration of the mesial temporal lobe and hypocamp, cerebral hypoxia and even after the aneurysm rupture of the posterior communicant artery, since they could observe in their study with 10 patients with amnesia for hypoxia and 10 for AcomA rupture, through neuropsychological measures gold standard for the memory.

Myers e cols. $(2008)^{9}$ valued 6 patients after hypoxia, 7 after AcomA ruptured and 13 controls in tasks of learning based in feedback. They noticed that the group AcomA was slow in the initial learning, but all the patients who completed the phase of the learning managed to generalize, as well as the controls. The group of the hypoxia did not differ from the controls in the task of learning, meantime they presented damage in the generalization. They point out that the learning based in feedback is different in patients with the same level of damage in the declarative memory, but etiologically different (hypoxia and AcomA).

On basis of the literature review, it is possible to be noticed that there are some studies referring cognitive alterations at several moments after the posterior communicant artery surgery. A great deal of them report alterations of intellectual, executive functions and memory (episodic and semantic). Mnestics alterations were considered same without damages in the traditionally connected areas and some authors explain these alterations like secondary to the executive dysfunction or even to the lack of blood irrigation in areas related to the memory. They also report secondary alterations to the temporary clipping (worse alert and selective attention) and to the duration of the clipping (worse alert and memory of short term). Some authors show that the deficits seems to reduce as time goes by, except with use of temporary clip where persistent deficits were observed in long term.

\section{References}

1. Akyuz M, Erylmaz M, Ozdemir C, Goksu E, Ucar T, Tuncer R. Effect of temporary clipping on frontal lobe functions in patients with ruptured aneurysm of the anterior communicating artery. Acta Neurol Scand. 2005;112(5):293-7. 
2. Bindschaedler C, Assal G, De Tribolet N. Cognitive sequelae following rupture of aneurysms of the anterior communicating artery and the anterior cerebral artery. Retrospective study of 56 cases. Rev Neurol (Paris). 1997;153(11):669-78.

3. D'Esposito M, Alexander MP, Fischer R, Mcglinchey-Berroth R, O'Connor M. Recovery of memory and executive function following anterior communicating artery aneurysm rupture. J Int Neuropsychol Soc. 1996;2(6):565-70.

4. Diamond BJ, De Luca J, Kelley SM. Memory and executive functions in amnesic and nonamnesic patients with aneurysms of the anterior communicating artery. Brain. 1997;120(6):1015-25

5. Hütter BO, Gilsbach JM. Early neuropsychological sequelae of aneurysm surgery and subarachnoid haemorrhage. Acta Neurochir (Wien). 1996;138(12):1370-8; discussion 1378-9.

6. Hütter BO, Kreitschmann-Andermahr I, Gilsbach JM. Health-related quality of life after aneurysmal subarachnoid hemorrhage: impacts of bleeding severity, computerized tomography findings, surgery, vasospasm, and neurological grade. J Neurosurg. 2001;94(2):241-51.

7. Mavaddat N, Sahakian BJ, Hutchinson PJ, Kirkpatrick PJ. Cognition following subarachnoid hemorrhage from anterior communicating artery aneurysm: relation to timing of surgery. J Neurosurg. 1999;91(3):402-7.

8. Myers CE, Deluca J, Hopkins RO, Gluck MA. Conditional discrimination and reversal in amnesia subsequent to hypoxic brain injury or anterior communicating artery aneurysm rupture. Neuropsychologia. 2006;44(1):130-9.
9. Myers CE, Hopkins RO, Hopkins RO, DeLuca J, Moore NB, Wolansky LJ, et al. Learning and generalization deficits in patients with memory impairments due to anterior communicating artery aneurysm rupture or hypoxic brain injury. Neuropsychology. 2008;22(5):681-6.

10. Rousseaux M, Godefroy O, Cabaret M, Benaim C, Pruvo JP. Analysis and course of cognitive deficits after rupture of aneurysms of the anterior communicating artery. Rev Neurol (Paris). 1996;152(11):678-87.

11. Silva SL. Avaliação da memória em pacientes póscirúrgicos de aneurisma cerebral [tese]. São Paulo: Unifesp; 1998. $255 \mathrm{p}$.

12. Simard S, Rouleau I, Brosseau J, Laframboise M, Bojanowsky M. Impact of executive dysfunctions on episodic memory abilities in patients with ruptured aneurysm of the anterior communicating artery. Brain Cogn. 2003;53(2):354-8.

13. Szatkowska I, Szumanska O, Grabowska A. The role of the human ventromedial prefrontal cortex in memory for contextual information. Neurosci Lett. 2004;364(2):71-5.

14. Thomas-Anterion C, Duthel R, Dirkx E, Koenig O, Baudoin V, Laurent $\mathrm{B}$, et al. Préservation de la mémoire procédurale chez dix-huit patients opérés d'un anévrisme de l'artère communicante antérieure. Neurochirurgie. 1996;42(1):54-60.

Endereço para correspondência

Eberval G. Figueiredo

Rua Eneas de Carvalho Aguiar, 255

05403-010 - São Paulo, SP 